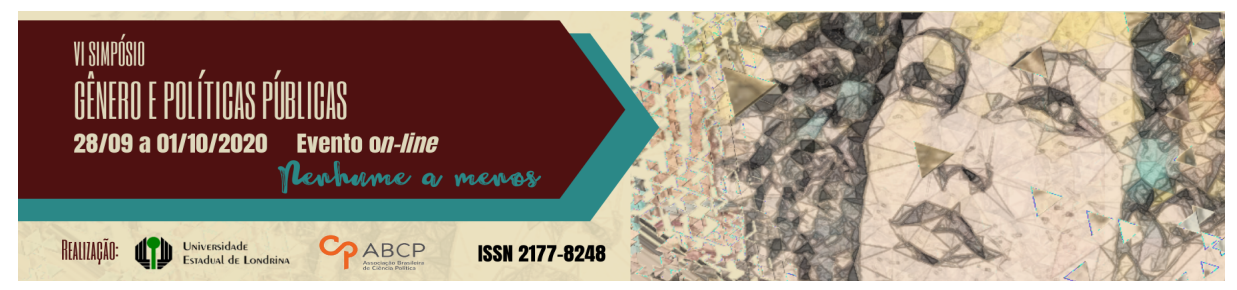

\title{
Envelhecimento feminino e o uso das Tecnologias da Informação e Comunicação
}

\author{
Daniela Soares da Silva ${ }^{1}$; Simone Pereira da Costa Dourado ${ }^{2}$
}

\section{Resumo}

Homens e mulheres vivenciam o envelhecimento de formas distintas, do mesmo modo, há diferenças na criação e no uso das Tecnologias da Informação e Comunicação (TIC). Assim, o objetivo deste artigo é entender se o uso das TIC pode ressignificar a velhice atentando-se também a possíveis melhorias na qualidade de vida a partir da integração aos processos de inovação tecnológica. Também buscamos compreender as diferenças nos usos das TIC por homens e mulheres idosas. A netnografia fez-se presente nesse processo, observamos o comportamento online de idosos e idosas em redes sociais, além da realização de um questionário online com perguntas diversas relacionadas ao uso da internet. Com o questionário online observou-se maior interesse feminino em assistir filmes e séries, beleza, artesanato e receitas. O interesse masculino ficou circunscrito às notícias diárias sobre diferentes assuntos e àquelas sobre esportes e somente os homens citaram que usam a internet para trabalho.

Palavras-chave: envelhecimento; gênero; tecnologias digitais.

1 Graduanda em Ciências Sociais pela Universidade Estadual de Maringá. E-mail: soaresilva105@gmail.com.

2 Doutora em Ciências Sociais pela Universidade do Estado do Rio de Janeiro (2003). Atualmente é professora associada do Departamento de Ciências Sociais, da Universidade Estadual de Maringá. E-mail: simone.dourado890@gmail.com.

GT 04 - Feminismo, tecnologia e mídias 


\title{
Female aging and the use of Information and Communication Technologies
}

\begin{abstract}
Men and women experience aging in different ways, similarly, there are differences in the creation and use of Information and Communication Technologies (ICT). Thus, the objective of this article was to understand whether the use of ICT can give a new meaning to old age while also looking at possible improvements in the quality of life from the integration of technological innovation processes. We also seek to understand the differences in the use of ICT by older men and women. Netnography was present in this process, we observed the online behavior of elderly men and women on social networks, besides the realization of an online questionnaire with several questions related to the use of the internet. Thus, we attested that there was a greater female interest in watching movies and series online, beauty, crafts and recipes. While men, they showed more interest in news, sports and just them mentioned that they use the internet for work.
\end{abstract}

Keywords: aging; genre; digital technologies.

\section{Introdução}

O termo velhice é fruto de uma construção social e não está restrito ao passar dos anos da vida humana. A categoria idosa, definida apenas por ter 60 anos ou mais, torna uniforme um grupo diverso, aspectos de classe, raça e gênero, por exemplo, diferenciam os indivíduos pertencentes a este grupo. Há diferenças até mesmo em relação a idade, dos 60 aos 75 anos alguns aspectos são observáveis, enquanto dos 75 até mais anos outras informações aparecem. Nem todos vivenciam o envelhecimento da mesma forma, assim, não há uma velhice única, mas velhices. Dentre os fatores que contribuem para as diferentes experiências de envelhecimento está o de gênero. Homens e mulheres vivenciam de forma diferente essa fase da vida, pois a socialização feminina e masculina é diferente entre si e se faz presente em todas as idades. De acordo com Fernandes e Garcia (2010) os homens idosos destacam a aposentadoria como um grande anunciador da chegada dessa fase da vida, já as mulheres associam o período à perda da beleza, muito associada à juventude. Ao destacar as preocupações com a beleza, as mulheres idosas evidenciam uma conjuntura que 
passaram a vida inteira, a da pressão estética, haja vista que as mulheres são condicionadas a lutar contra o tempo que traz consigo as tão temidas rugas, reprovadas socialmente. Já os homens idosos, ao destacar a aposentadoria como grande anunciador da senioridade, explicitam que ao deixar o sistema produtivo também deixam a vida social ligada à juventude e aos lucros, eles deixam de ser úteis ao capital. Ao homem é destinada a função de ser o provedor do lar e ao chegar na terceira idade, ao deixar os postos de trabalho sente-se inerte. Diferente das idosas, eles não têm a função explícita de cuidar do lar, sendo assim, não é possível compensar o tempo, agora ocioso, nas atividades domésticas.

Estatísticas do Brasil e do mundo apontam para a feminização da velhice. Além disso, homens e mulheres que hoje são idosos tiveram trajetórias de vida distintas o que influencia na maneira como o envelhecimento será vivenciado. A velhice para as mulheres é diferente em relação aos homens, visto que, além do envelhecimento elas têm que lidar com as discriminações de gênero. Para elas esse período também pode ser marcado pela solidão, o estado conjugal entre idosos e idosas não é proporcional, na terceira idade os homens têm mais possibilidades de encontrar uma parceira, por vezes mais nova. Se a mulher idosa for negra soma-se o racismo a esta equação, elas em todas as idades tendem a ser preteridas, pois homens brancos e negros em geral, escolhem mulheres brancas para se casar. Ainda em relação a cor, idosas negras e pardas são 36,0\% enquanto idosas brancas são 61,1\% dentre 8 milhões, as mulheres negras em toda a vida estão mais expostas a morbidade e mortalidade o que pode nos explicar tais estatísticas (BATISTA; MOTTA, 2014). Assim, os feminismos consideram questões de raça e classe, mas será que o fazem igualmente em relação a questões geracionais? Alda Britto da Motta em seu trabalho de título provocador PVC-Bicho papão para as feministas (a sigla PVC para a autora seria "a po**a da velhice chegando) questiona o lugar da velhice no feminismo, para a autora a condição de gênero tem sido definidora na vida dos idosos, pois, 
"ser velho é, em boa parte, ser mulher" (MOTTA, 1998, p. 139). Assim, é preciso pensar de forma concreta a situação de vida dessas mulheres para propor melhorias em sua qualidade de vida.

As teorias feministas em sua maioria têm visado a inclusão, o feminismo não pode ficar restrito às mulheres brancas, heterossexuais e jovens. Como sabemos, a "mulher universal" não existe, existem mulheres diversas, diferentes em suas vivências. Todavia, políticas públicas voltadas para mulheres, em geral, ao tratar da saúde e sexualidade feminina, por exemplo, têm focado no período reprodutivo, assim, as mulheres que estão fora dessa faixa etária acabam excluídas das discussões. De acordo com o estudo de Batista e Mota (2014), são recentes os documentos relacionados as políticas públicas que consideram a diversidade geracional feminina. O primeiro Plano de Política Pública para Mulheres (PNPMs), de 2005, não fez referência clara às mulheres idosas e não incluiu em seus grupos de trabalho nenhum representante de qualquer órgão ligado às questões referentes às pessoas idosas. Já no segundo

PNPM, de 2007, mais abrangente, incluiu em uma de suas áreas estratégicas o "Enfrentamento das desigualdades geracionais que atingem mulheres com especial atenção às jovens e idosas" além de fazer referência à questão geracional também em outras áreas. No entanto, para as autoras, mesmo que o movimento feminista tenha se voltado às questões geracionais, estas ainda aparecem de forma tênue nos debates. É preciso então, pensar um movimento feminista "antietarista" que abrange mulheres em suas totais especificidades, incluindo as relacionadas à idade.

Assim, o objetivo deste artigo é verificar se o uso das TIC pode ressignificar a velhice, além de verificar se mulheres idosas fazem uso desses espaços virtuais, com qual frequência e para quais fins. Buscamos entender se o uso das TIC pode constituir uma ponte entre gerações marcadas pelo conflito, como aquele que opõe idosos e jovens, e, ainda, se o uso das TIC recriou espaços de convivência entre esses diferentes grupos geracionais. Além disso, buscamos identificar se o uso das TIC 
pode contribuir como uma forma de integração da população idosa aos processos sociais atuais, pois, o uso das Tecnologias da Informação e

Comunicação torna possível a expressão de opinião, além do acesso a informações por meio das redes. Ademais, tivemos como objetivo entender as diferenças entre a utilização das TIC por homens e mulheres idosas. Inicialmente, cumpriríamos esse objetivo, também, por meio de entrevistas presenciais a fim de atingir uma compreensão mais aprofundada e diversa sobre a temática, contudo, devido à pandemia de COVID-19 fez-se necessário uma mudança metodológica.

Dessa forma, a metodologia utilizada neste estudo consistiu em revisão bibliográfica e coleta de dados etnográficos por meio de netnografia empreendida em redes sociais. Assim, encontramos um grupo no Facebook destinado a idosos e administrado por eles, o grupo encontrado possui características semelhantes às de uma "comunidade online" como proposta por Howard Rheingold (1993). Para o autor comunidades online são agregações sociais que surgem da rede, isto é, não são somente fruto de interações virtuais de poucos indivíduos sendo coletivas, além disso, é preciso que esse grupo de pessoas interaja ao longo do tempo para que seja possível a criação de laços entre os internautas. Assim, o campo de pesquisa da netnografia não está restrito a um espaço físico como uma cidade ou estado, no grupo observado as interações aconteciam entre pessoas de diferentes lugares do Brasil, o campo de estudo nesse sentido é baseado nas características de uma comunidade online para além dos critérios de definição de um campo de pesquisa no espaço geográfico. O grupo para idosos observado foi criado em 2014, está no ar há mais de cinco anos e possui cerca de 1.700 membros, as interações entre os participantes do grupo são diárias e muitos buscam interagir para fazer amizades por meio dos contatos no grupo. Através do grupo realizamos a parte netnográfica dessa pesquisa e de acordo com os objetivos propostos e bibliografia inventariada selecionamos os principais elementos a serem apresentados nos resultados desse estudo. 
Além disso, realizamos por meio da plataforma de formulários disponibilizada pela Google, durante os meses de dezembro de 2019 e março de 2020, um questionário com 17 perguntas, as quais as respostas em sua maioria eram de múltipla escolha a fim de facilitar e diminuir o tempo para respostas. O questionário foi divulgado principalmente em redes sociais como Twitter, Instagram e Facebook, além de aplicativos de mensagens como WhatsApp, o meio online para divulgação do questionário vai ao encontro dos avanços tecnológicos atuais. $\mathrm{O}$ uso desse aparato facilitou o acesso aos informantes em diferentes cidades economizando tempo e recursos, contudo, as respostas ao formulário em alguns casos foram feitas com auxílio de terceiros, em sua maioria jovens da família do informante, evidenciando a dificuldade em lidar com a plataforma de questionários utilizada na pesquisa. $O$ uso de redes sociais e aplicativos de mensagens como WhatsApp é amplamente difundido entre os brasileiros e seu uso acontece de forma intuitiva diferente de outros recursos da internet, já para o grupo pesquisado, abrir um link e responder aos questionários pode não ser tão facilmente acessível.

Ademais, a etnografia é uma forma de pesquisa qualitativa muito ligada à antropologia e, de forma sucinta, podemos afirmar que ela abrange a descrição e interpretação dos acontecimentos da vida do grupo estudado, assim, o trabalho de campo se torna um recurso essencial para o pesquisador, possibilitando a compreensão das dinâmicas de uma sociedade com profundidade e, em geral, os dados da pesquisa são coletados por meio da observação participante (GODOY, 1995). O surgimento da etnografia trata em geral de um outro distante, Malinowski (1978), por exemplo, se deslocou até as Ilhas Trobriand para finalmente escrever a obra de grande importância para a antropologia Os Argonautas do Pacífico Ocidental, ainda nos anos de 1940. Atualmente, entretanto, os estudos etnográficos têm sido feitos em comunidades muito próximas, o rito de passagem para os futuros antropólogos já não consiste mais em longas viagens, novas formas de fazer antropologia têm surgido, dentre elas, a etnografia na internet ou netnografia. Robert Kozinets em seu livro Netnografia: Realizando 
pesquisa etnográfica online define a netnografia como "[...] pesquisa observacional participante baseada em trabalho de campo online. Ela usa comunicações mediadas por computador como fonte de dados para chegar à compreensão e à representação etnográfica de um fenômeno cultural ou comunal"' (KOZINETS, 2014, p. 62).

Para Polivanov (2013) a pesquisa na internet tem uma forma diferente de interação entre o pesquisador e o grupo estudado, a observação participante, assim, é diversa da proposta por Malinowski (1978), sendo possível que o pesquisador somente observe o cenário virtual, ou que ele também participe e interfira neste. De qualquer forma, a observação intermediada pela tecnologia trará resultados distintos daqueles coletados presencialmente, a internet possui linguagem própria devido aos recursos da rede, o uso de emoticons, fotografias e gírias durante uma conversa online muda o conteúdo da observação do pesquisador, essas diferenças justificam a utilização de um termo específico para pesquisas em ambiente online.

\section{A expansão tecnológica e suas relações com questões geracionais e de gênero}

O jovem do século XXI cresceu em meio a ascensão tecnológica exponencial, ainda na infância muitos tiveram acesso aos vídeos games, computadores, celulares e tablets. Tais aparatos tecnológicos mudaram a relação das pessoas com o mundo, rolar o feed de notícias de uma rede social é uma habilidade quase inata aos "nativos digitais", nascidos na era da informatização, a estrutura de pensamento, a visão de mundo e a forma de aprendizado destes é compatível com a timeline das redes sociais. Essa habilidade é necessária em vários aspectos da vida cotidiana, utilizamos tais inovações tecnológicas para o trabalho, os estudos e a socialização. Todavia, nem todos, na contemporaneidade, acessaram de imediato os aparatos tecnológicos. Os "imigrantes digitais", nascidos fora do auge tecnológico, aprenderam a linguagem do ambiente permeado de redes sociais tardiamente, para estes a lógica de rolagem infinita de feeds não é congênita. No processo de 
aprendizagem de um novo idioma é natural a permanência de um sotaque, um pé no passado. Quando falamos de aparatos tecnológicos o "sotaque do imigrante digital" é percebido pela forma de acesso à internet, a maneira de lidar com instruções de uso, até mesmo o conteúdo de postagens e a utilização de uma rede social ou outra. Atualmente, os mais velhos estão aprendendo a nova linguagem tecnológica, isso significa que essas informações apreendidas posteriormente irão para uma área diferente do cérebro, distinto do que acontece com os nativos digitais (PRENSKY, 2001). A relação entre a expansão tecnológica e o processo de envelhecimento moderno é complexa, tanto a população idosa mundial quanto as TIC crescem exponencialmente, as tecnologias já dominam o cotidiano da sociedade atual e como os imigrantes digitais lidam com a ascensão tecnológica é um campo teórico rico.

Entretanto, as diferenças na forma de lidar com a tecnologia não ficam restritas às diferenças geracionais, homens e mulheres têm experiencias diferentes com tais inovações. Os dados do sistema educativo e os da área empresarial indicam que a presença feminina nos estudos e profissões relacionadas com as Tecnologias da Informação e Comunicação (TIC) continua a ser minoritária. Os homens criam e gestionam as inovações digitais e as mulheres são utilizadoras dessas inovações, o que pode aumentar a exclusão de gênero numa sociedade onde as TIC são um pilar fundamental da comunicação, da ciência, da cultura, e até mesmo da economia. Uma hipótese que explica o porquê dessa diferença entre homens e mulheres em relação a tecnologia é a de que a socialização feminina ainda direciona mulheres para áreas diferentes das tecnológicas, áreas voltadas para o cuidado, como enfermagem por exemplo, além disso, a velocidade na qual as TIC são inseridas na sociedade é superior àquela correspondente à emancipação feminina (JIMENÉZ; FERNÁNDEZ, 2016). É importante destacar que, apesar de participarem pouco da geração dessas novas tecnologias, as mulheres utilizam as Tecnologias da Informação e Comunicação, sendo possível que as TIC sejam uma forma de ressignificar a velhice feminina, como exposto no estudo de Loe (2010) sobre nonagenárias em New 
York. A pesquisa informa que os usos que essas mulheres fazem das tecnologias podem gerar formas de conhecimento que reinventam a velhice e fazem dessas ferramentas um instrumento de poder e autonomia não experimentados antes. Em geral, as inovações tecnológicas não são pensadas para a terceira idade, mas podem ser utilizadas por ela, por vezes passando por ajustes e ressignificação. As mulheres idosas por meio das tecnologias podem atuar no mundo apesar da falta de mobilidade e até mesmo saúde física advindas da longevidade.

O estudo de Graner-Ray e Marston (2016) presente no livro Ageing and Technology: Perspectives from Social Sciences que tratou da participação de mulheres com mais idade nos games, evidenciou que apesar das limitações impostas à terceira idade, seja pela longevidade ou pelos estereótipos que cercam essa fase da vida, os jogos digitais têm sido uma alternativa de lazer. Os jogos digitais podem proporcionar um estimulo à criatividade, acesso a novos conhecimentos, sendo uma forma de se manter ativo mesmo com limitações físicas. A saúde mental dos jogadores pode melhorar com as interações sociais e estímulos proporcionados pelos jogos, principalmente os online. Contudo, apesar da população idosa aderir às tecnologias e com elas aos jogos, a comunidade de jogadores ainda é em sua maioria composta por jovens e homens. Assim, poucos trabalhos voltam-se para as preferências dos idosos nos jogos digitais e menos ainda se voltam para as preferências das mulheres idosas nos games. Sabe-se que mulheres de todas idades compõem a minoria dos jogadores de jogos digitais, contudo:

a idade média das jogadoras americanas mudou consideravelmente nos últimos 15 anos com base nas estatísticas publicadas pela ESA. A idade média de uma jogadora em 2004 era de 29 anos (ESA 2004) e onze anos depois, a idade média de uma jogadora agora é de 43 anos, enquanto a idade média de um jogador masculino é de 35 anos (ESA, 2015) (GRANER-RAY; MARSTON, 2016, p. 68).

Mesmo que haja atualmente maior esforço para mudanças neste cenário a área de tecnologia é predominantemente masculina, eles 
elaboram jogos cujo conteúdo pode ser menos interessante para mulheres. Tradicionalmente as personagens femininas são representadas de forma estereotipada nesses jogos, quando não são donzelas em perigo são hipersexualizadas, além disso, nos jogos online, a comunidade de jogadores pode ser hostil com as jogadoras, afastandoas. Dessa maneira, há diferenças no uso que homens e mulheres idosas fazem da tecnologia e por conseguinte dos jogos digitais, entre as mulheres idosas os principais jogos são os de "quebra-cabeça", enquanto RPG e jogos de estratégia são majoritariamente masculinos (GRANER-RAY; MARSTON, 2016, p.81).

Durante a nossa pesquisa sobre Envelhecimento Feminino e o uso das Tecnologias da Informação e Comunicação feita entre agosto de 2019 e junho de 2020 entendemos que uma das redes sociais mais utilizadas, sendo uma das principais fontes de interação entre idosos na rede, é o Facebook. Por meio da plataforma encontramos um grupo feito por idosos e destinado a eles, criado em 2014 possui cerca de mil e setecentos membros do Brasil todo. Todos os membros podem postar no grupo, porém, há regras, como exposto por seu criador na página inicial do grupo:

PRECISO SABER QUAL A SUA INTENÇÃO ? ESSE GRUPO É PUBLICO PODE PARTICIPAR " SEJA ELE OU ELA " FIQUE A VONTADE, PARA POSTAGENS DE FOTOS, OU QUALQUER TIPO DE ARQUIVO QUE ESTEJA DENTRO DO PADRÃO DO GRUPO ; NÃO É PERMITIDO TRAJES DE BANHO NEM PALAVRÕES NEM CONTEÚDO PORNOGRÁFICO; O RESPEITO É BOM E TODOS NÓS GOSTAMOS COMBINADOS? ENTÃO VAMOS NÓS !!!! (Administrador e criador do grupo para idosos no Fabebook).

O uso de letras maiúsculas pelo criador e administrador membro do grupo pode ser entendido como parte de seu sotaque como imigrante digital. Enquanto os mais jovens cujo cotidiano foi moldado de acordo com as TIC podem entender, em geral, o uso de letras maiúsculas como uma forma de dar ênfase a uma palavra ou frase, para os mais velhos e menos habituados com as inovações tecnológicas o 
recurso pode ser ressignificado. A utilização das letras maiúsculas por idosos pode não estar relacionada a ênfase, mas a facilitação da leitura por meio das letras maiores, visto que, na terceira idade pode haver a diminuição da acuidade visual (LEITÃO et al, 2019).

Assim, seguindo as regras do grupo, as postagens em sua maioria são compostas por imagens de bom dia e frases religiosas, em sua maioria as postagens e comentários são feitos por mulheres. Caso os membros não cumpram as ordens podem ser banidos do grupo. Além das imagens de bom dia, alguns membros, principalmente os do sexo feminino, compartilham suas próprias fotos, muitas(os) recebem elogios dos colegas de grupo, o flerte se fez presente em várias postagens, algumas são explicitamente feitas com esse objetivo, nestas, os participantes colocam uma foto e compartilham na legenda informações como idade, cidade em que reside e até mesmo sua religião. Nos comentários os(as) interessados(as) pedem o número de telefone para contato, colocam emoticons de corações, tudo com muito respeito. Além do interesse romântico, há aqueles que compartilham suas fotos com o intuito de fazer novos amigos, geralmente estes são os mais velhos do grupo. Em suma, o objetivo central da maioria das postagens é interagir, visto que, a solidão é uma queixa frequente entre os membros do grupo como exposto em posts sobre solidão, os quais contam com os comentários dos membros que por meio da plataforma prestam apoio, se identificam, concordam e dão até mesmo dicas para combater a solidão.

Ademais, por meio do grupo alguns integrantes expressaram suas opiniões políticas evidenciando que por meio das redes sociais é possível continuar se informando e integrar-se aos processos sociais atuais para assim opinar sobre eles. Os idosos que utilizam as TIC podem atuar na sociedade durante toda a fase da vida, mesmo com possíveis adversidades físicas, fazendo-se cumprir o tratado no plano internacional de ação para o envelhecimento de 2003, o qual propôs além do reconhecimento das contribuições dos idosos à sociedade a manutenção na participação deles ativamente em tomadas de decisões em todos os níveis (ORGANIZAÇÃO DAS NAÇÕES UNIDAS, 2003, p. 
35). As redes sociais, então, têm sido uma forma de convívio para esses idosos apesar da distância, visto que foi observado que as interações entre os membros do grupo ficam restritas ao ciberespaço e muitas acontecem entre pessoas de estados diferentes sem que isso seja um empecilho. O contato entre os membros é real, mesmo que não seja presencial.

Além disso, a interação proporcionada pelas TIC têm sido uma fonte de convívio também fora das redes sociais, as TIC são parte da vida dos jovens desde muito cedo, eles sabem utilizar dessas ferramentas com facilidade e ajudam os mais velhos a entende-las, os filhos e netos, em geral, são os responsáveis por ensinar os avós e os pais a utilizar as novas tecnologias. Assim, a tecnologia proporciona um momento de interação entre as gerações também para além do ciberespaço, atuando como uma ponte entre gerações marcadas por conflito, há uma relação entre nativos digitais e imigrantes digitais que buscam aprender essa nova linguagem. Na pesquisa que fizemos, alguns informantes precisaram do auxílio de seus netos para responder ao questionário, um deles inclusive enviou um registro por foto do momento em que auxiliou a avó nas respostas.

O estudo de Leitão et al (2019) utilizando-se de dados etnográficos coletados no Facebook e no curso de informática para a Melhor Idade ofertado pelo laboratório de informática da PRAE/CPD da UFSM no ano de 2016 tratou da relação dos mais velhos com a tecnologia. Diferenças geracionais também se fizeram presente na pesquisa, pois, enquanto os estudantes eram em sua maioria pessoas com mais de 50 anos, os professores eram jovens de cerca de 20 anos. Ademais, diferente de outros cursos ofertados pela instituição para ser um professor de informática para a melhor idade não é necessário ter especialização, o saber tecnológico nesse sentido estaria relacionado ao pertencimento a uma geração que desde a infância teve contato com as TIC, o saber digital seria como um estilo de vida a ser passado adiante, não é algo técnico a ser ensinado por especialistas qualificados, parte-se do princípio que ser jovem é saber lidar com as TIC. Ainda de acordo com Leitão et al. (2019) a busca pelo entendimento das TIC pelos idosos 
tem como base a manutenção das relações familiares e a necessidade de integração às inovações tecnológicas, no caso das idosas elas buscavam por meio da tecnologia estreitar os laços com seus netos. Além do interesse pela tecnologia, a construção de laços entre os participantes das turmas se fez presente, evidenciando que as TIC podem contribuir para a manutenção da qualidade de vida do idoso ampliando sua teia de relações sociais.

\section{Dados do questionário destinado a pessoas com mais de 60 anos sobre o uso de tecnologia: uso que as mulheres idosas fazem das TIC}

A partir da revisão bibliográfica sobre envelhecimento e o uso das TIC criamos um questionário online sobre a temática para que por meio de redes sociais como Instagram, Facebook, Twitter e aplicativos de mensagens como WhatsApp divulgássemos as 17 questões sobre o tema a fim de verificar por meio das respostas diferenças no uso da tecnologia por homens e mulheres idosas. A princípio iriamos contatar os informantes do questionário para que realizássemos entrevistas presenciais a fim de aprofundar os dados obtidos por meio das respostas diretas do formulário, infelizmente devido à pandemia mundial de COVID-19 isso não foi possível, sendo necessário a substituição dessa fase da pesquisa.

O primeiro grupo de perguntas do questionário foi sobre os dados pessoais dos informantes, perguntas como nome, telefone, cidade em que reside foram feitas para que fosse possível contatá-los posteriormente para a fase de entrevistas presenciais. Também perguntamos o sexo dos informantes para que fosse possível identificar possíveis diferenças nas respostas quanto ao uso das TIC, perguntas referentes às fontes de renda e escolaridade foram feitas para que também pudéssemos entender o perfil socioeconômico dos informantes. Por fim, realizamos questões sobre o uso da internet pelos informantes, quanto tempo ficam conectados e por quais dispositivos, possibilitando que de acordo com as respostas fosse possível estabelecer 
diferenças entre homens e mulheres e idosas quanto a utilização das TIC.

Assim, obtivemos 24 respostas de pessoas com idades entre 57 e 76 anos, sendo 18 do sexo feminino (75\%) e seis do sexo masculino (25\%). Recebemos respostas de diferentes estados como São Paulo, Santa Catarina, Mina Gerais além do Paraná. Ademais, dez $(41,7 \%)$ pessoas responderam que acessavam a internet pelo computador e pelo celular, outras 14 (58,3\%) pessoas utilizavam somente o celular para se conectar, nenhum dos informantes afirmou usar somente o computador. Tais dados corroboram o evidenciado por Fernández Ardèvol (2019), em termos de custo e facilidade de utilização, o celular é mais acessível aos idosos, sendo também o dispositivo mais utilizado para o acesso à rede em todas as faixas etárias. É possível utilizar o celular sem acesso prévio a um computador, sendo mais fácil aprender a usar o dispositivo móvel que já faz parte do cotidiano de milhares de brasileiros.

Ao analisar esses dados considerando o gênero dos informantes é observável algumas diferenças nas respostas masculinas e femininas. Quando questionados para quais fins utilizam a internet nenhum homem afirmou utilizar a rede para assistir filmes ou séries, enquanto $33 \%$ delas marcaram essa opção. Quanto aos jogos, 17\% deles marcaram que usam a internet para tal, enquanto $22 \%$ delas também marcaram essa opção. Somente elas afirmaram usar a tecnologia para fins religiosos, 33\% alegaram acessar conteúdos religiosos nas redes, eles, ao contrário, não marcaram nenhuma vez essa opção. Ademais, somente eles acrescentaram outras opções de uso, sendo estas: Trabalho e mapas e serviços de transportadora. Nenhuma informante do sexo feminino citou trabalho durante o questionário. 
Gráfico 1 - Para quais fins os homens idosos usam a internet

Mapas, serviços de transportadora

E-mail

Trabalho

Sites de relacionamento

Sites de conteúdos religiosos

Redes sociais

Jogos

Assistir filmes e séries

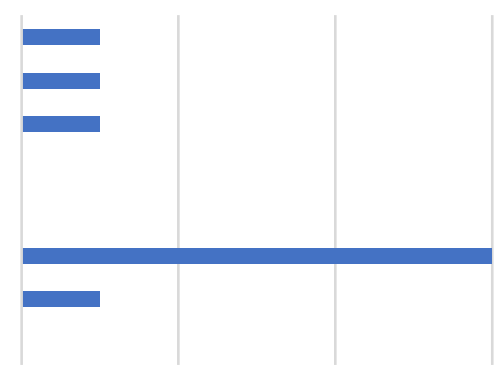

Fonte: Questionário realizado via internet

Gráfico 2 - Para quais fins as mulheres idosas usam a internet

sites de relacionamento

sites de conteúdos religiosos

redes sociais

jogos

Assistir filmes e séries

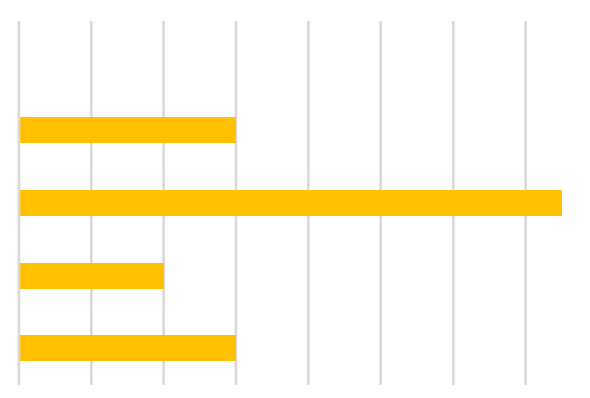

Fonte: Questionário realizado via internet.

Todos informantes do sexo masculino afirmaram que utilizam a internet para pesquisas, já entre elas, somente $78 \%$ afirmou utilizar a rede para esse fim. $17 \%$ dos homens afirmaram fazer pesquisas acadêmicas, enquanto $11 \%$ delas alegou fazer esse mesmo tipo de pesquisa. Quanto às receitas, elas pesquisam mais sobre esse assunto do que eles, 55\% das mulheres afirmaram fazer buscas relacionadas a receitas, contra apenas 33\% deles. Somente elas afirmaram pesquisar sobre moda (17\% delas marcaram essa opção, enquanto nenhum homem marcou essa opção). $83 \%$ dos informantes do sexo masculino 
afirmaram fazer buscas por notícias, enquanto somente $44 \%$ delas afirmaram fazer o mesmo. Somente $17 \%$ deles pesquisam sobre saúde, por outro lado, $44 \%$ delas pesquisam sobre o assunto. Nenhuma mulher marcou a opção "esportes" como um de seus temas de pesquisa, já entre os homens metade deles marcaram essa opção. Eles pesquisam menos do que elas sobre lazer, $17 \%$ dos homens marcaram essa opção, já dentre elas $28 \%$ marcaram. $17 \%$ deles pesquisam sobre segurança, contra somente 5\% delas. Eles acrescentaram outras opções além das listadas no questionário, adicionando novamente o trabalho e pesquisas relacionadas a política, já nos acréscimos feitos pelas informantes mulheres há beleza e artesanato. Com isso, é observável os diferentes usos da tecnologia por homens e mulheres, eles pesquisam mais sobre notícias e esportes, enquanto elas pesquisam mais sobre receitas, saúde e notícias.

Gráfico 3 - Sobre quais assuntos homens idosos pesquisam

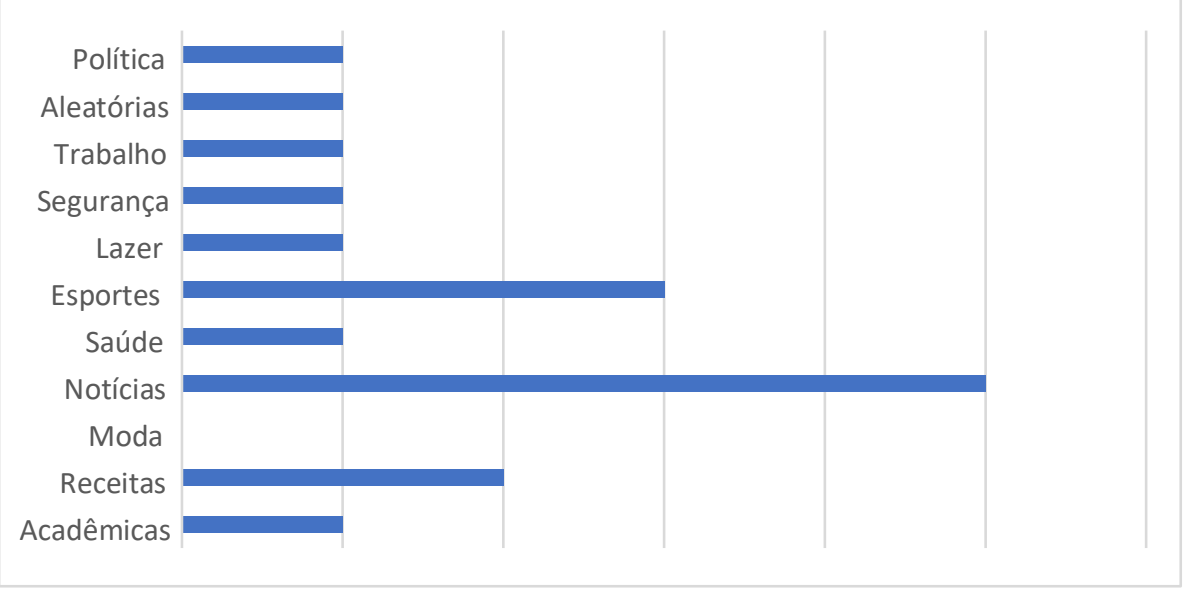

Fonte: Questionário realizado via internet. 
Gráfico 4 - Sobre quais assuntos mulheres idosas pesquisam

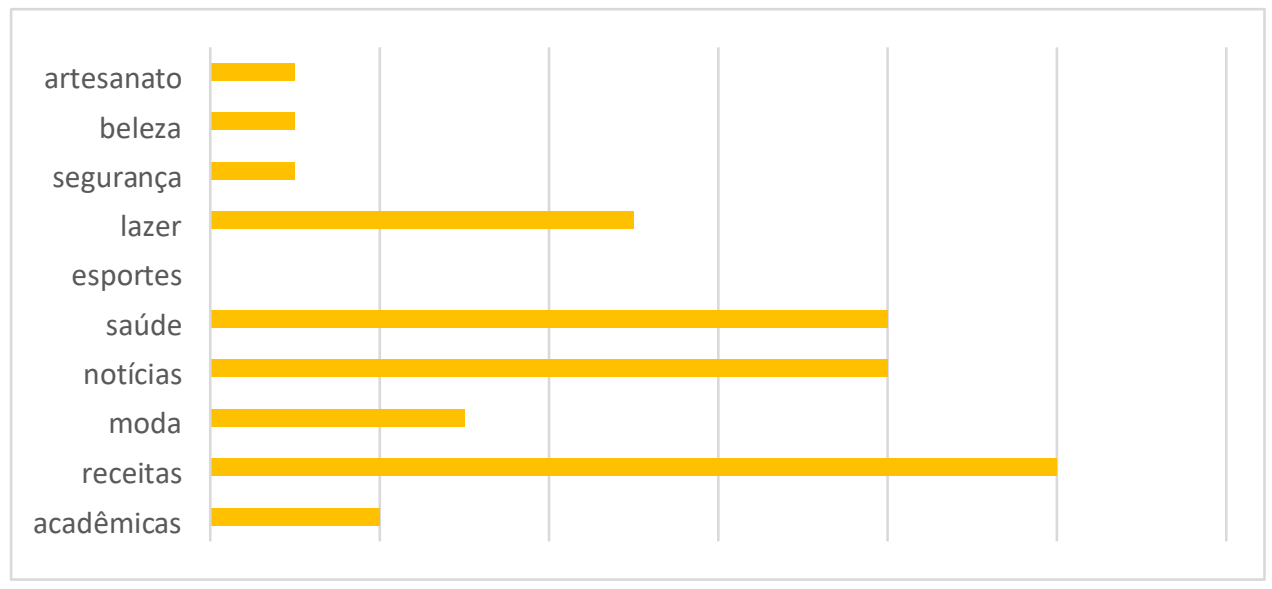

Fonte: Questionário realizado via internet.

De acordo com dados da Pesquisa Nacional por Amostra de Domicílios, homens com 60 anos ou mais anos compunham 4,9\% daqueles que com 10 ou mais anos utilizaram a internet nos três meses de referência em 2015, enquanto elas compunham 5,1\%. Do mesmo modo, do grupo de pessoas com 10 anos ou mais que possuíam telefone móvel celular para uso pessoal, os homens de 60 ou mais anos de idade compunham $11,5 \%$, enquanto as mulheres idosas dessa mesma faixa etária totalizaram $12,4 \%$. Elas são maioria quando o assunto é o uso de TIC, porém, com diferenças quantitativas pouco marcantes, idosos e idosas quantitativamente têm o mesmo acesso às Tecnologias da Informação e Comunicação (TIC) as diferenças aparecem nas diferentes formas de uso, como já exposto.

\section{Conclusão}

O envelhecimento da população mundial é um fato, países do mundo todo assistem a pirâmide etária mudar seu formato, a população idosa na maioria dos países cresce em número ano após ano. Assim, durante esta pesquisa pensamos sobre esse processo, envelhecer pode 
significar uma vitória, a diminuição da mortalidade, o avanço da medicina no tratamento de doenças que antes eram fatais. Contudo, o envelhecimento também pode significar perdas quando não há a manutenção da qualidade de vida. $\mathrm{O}$ conceito de qualidade de vida possui múltiplos significados, está relacionado à capacidade física, acesso a bens de consumo, à cultura, educação, interações sociais e outros, na terceira idade não é diferente. Assim, concluímos que o acesso às Tecnologias da Informação e Comunicação podem ajudar na manutenção da qualidade de vida dos idosos e até mesmo em sua saúde, visto que a internet é uma nova dimensão da vida social, por meio da qual os indivíduos interagem, compartilham ideias e informações em tempo real pelo mundo todo. Desse modo, entendemos que há uma relação entre o acesso às TICs e a qualidade de vida dos idosos, ao utilizar essa ferramenta eles se comunicam com maior frequência com familiares, ocupam o tempo livre com atividades em meios digitais diminuindo a solidão além acessarem os mais diversos conteúdos.

Todavia, o acesso e utilização das TIC não acontece de maneira uniforme, com este estudo identificamos diferentes usos dos aparatos tecnológicos por homens e mulheres idosas. Também exploramos diferenças geracionais em relação as TIC, com a ascensão da tecnologia no cotidiano mundial, os jovens passaram a ter um papel ativo na passagem do conhecimento aos mais velhos, gerando uma forma de interação entre gerações distintas.

Para trabalhos futuros faz-se necessária a coleta de dados também fora do ciberespaço, além da ampliação em número dos informantes para que o tema seja compreendido em sua total complexidade.

\section{Referências}

BATISTA, Carla Gisele; MOTTA, Alda Britto da. Velhice é uma ausência? Uma aproximação aos feminismos e à perspectiva 
geracional. Revista Feminismos, Salvador - Ba, v. 2, n. 1, p. 37-46, abr. 2014.

CALIXTO, Douglas de Oliveira. Memes na internet: entrelaçamentos entre educomunicação, cibercultura e a 'zoeira' de estudantes nas redes sociais. 2017. 151f. Dissertação (Mestrado em Ciências da Comunicação) - Programa de Pós-Graduação em Ciências da Comunicação; Escola de Comunicação e Artes, Universidade de São Paulo, São Paulo, 2017.

DUARTE, Rosália. Pesquisa Qualitativa: Reflexões sobre o trabalho de campo. Cadernos de Pesquisa, Rio de Janeiro, n. 115, p. 139-154, mar. 2002.

FERNANDES, Maria das Graças Melo; GARCIA, Loreley Gomes. O Sentido da Velhice para Homens e Mulheres Idosos. Saúde Soc, São Paulo, v. 19, n. 4, p. 771-783, 2010.

FERNÁNDEZ-ARDÈVOL, Mireia. Práticas digitais móveis das pessoas idosas no Brasil: dados e reflexões. Panorama setorial da Internet, n. 1 p. 1-18, mar. 2019. Disponível em: https://www.cetic.br/media/docs/publicacoes/1/panorama_esten dido_mar_2019_online.pdf. Acesso em: 25 mar. 2020.

GODOY, Arilda Schmidt. Pesquisa Qualitativa: Tipos Fundamentais. Revista de Administração de Empresas, São Paulo, v. 35, n.3, p. 20-29 mai./jun. 1995.

GRANER-RAY, Sheri; MARSTON, Hannah. Older Women on the Game: understanding digital game perspectives from an ageing cohort. In: DOMÍNGUEZ-RUÉ, Emma; NIERLING, Linda (ed.). Ageing and Technology: perspectives from the social sciences. Bielefeld: Transcript Verlag, 2016. p. 67-91. Disponível em: https:/ / transcript.degruyter.com/view/title/511609?language=en. Acesso em: 29 jun. 2020.

INSTITUTO BRASILEIRO DE GEOGRAFIA E ESTATÍSTICA. Pesquisa Nacional por Amostra de Domicílios 2015. Tabela 4820 - Pessoas de 10 anos ou mais de idade que utilizaram a Internet, no período de referência dos últimos três meses, total, distribuição e percentuais, por sexo e grupos de idade. Brasília, DF, 2015. Disponível em: https://sidra.ibge.gov.br/Tabela/4820. Acesso em: 25 mar. 2020. 
INSTITUTO BRASILEIRO DE GEOGRAFIA E ESTATÍSTICA. Pesquisa Nacional por Amostra de Domicílios 2015. Tabela 4843 - Pessoas de 10 anos ou mais de idade que tinham telefone móvel celular para uso pessoal, total, distribuição e percentual, por sexo e grupos de idade. Brasília, DF, 2015.2 Disponível em: https:/ / sidra.ibge.gov.br/Tabela/4843._Acesso em: 25 mar. 2020.

JIMÉNEZ, Rafael; FERNÁNDEZ, Carmen. La brecha de género en la educación tecnológica. Ensaio: aval. pol. públ. Educ., Rio de Janeiro, v. 24, n. 92, p. 743-771, jul./set. 2016.

KOZINETS, Robert V. Netnografia: realizando pesquisa etnográfica online. Porto Alegre: Penso, 2014.

LEITÃO et al. Pegando o jeito de domar o bicho: o processo de aprendizagem das tecnologias digitais por idosos. Rev. Antropol. São Paulo, v. 62, n. 3, p. 652-658, 2019.

LOE, Meika. Doing it my way: old women, technology and wellbeing. Sociology of Health \& Illness, v. 32, n. 2, p. 319-334, 2010.

MALINOWSKI, Bronislaw. Argonautas do Pacífico Ocidental. São Paulo: Abril Cultural, 1978.

MOTTA, Alda Britto da. PVC - Bicho-papão para as Feministas? In: PASSOS, Elizete; ALVES, Ivia; MACÊDO, Márcia (Org.). Metamorfoses: Gênero na perspectiva interdisciplinar. 3. ed. Salvador Ba: Ufba, Núcleo de Estudos Interdisciplinares Sobre A Mulher, 1998. Cap. 11. p. 137-145.

ORGANIZAÇÃO DAS NAÇÕES UNIDAS. Plano de ação internacional contra o envelhecimento, 2002/ Organização das Nações Unidas; tradução de Arlene Santos. -- Brasília : Secretaria Especial dos Direitos Humanos, 2003. - 49 p. : 21 cm. - (Série Institucional em Direitos Humanos; v. 1).

PRENSKY, M. Digital Native, digital immmigrants. Digital Native immigrants. On the horizon, MCB University Press, v. 9, n. 5, Oct. 2001.

POLIVANOV, Beatriz. Etnografia virtual, netnografia ou apenas etnografia? Implicações dos conceitos. Esferas, Brasília, ano 2, n. 3, p. 61-71, jul./dez. 2013.

RHEINGOLD, Howard. The Virtual Comunity: Homesteading on the Electronic Frontier. Reading -MA: Addison-Wesley, 1993. 